\title{
Human Resources Management - the Example of Wilderness Guides
}

\author{
Josef ŠTEMBERK, Kamil KUČA \\ University of Hradec Králové, Hradec Králové, Czech Republic \\ \{josef.stemberk, kamil.kuca\} @uhk.cz
}

\begin{abstract}
The aim of the paper is to introduce the possibilities of managing the development of new tourism activities associated with visits to national parks. Sustainable activities, especially in large-scale protected areas, which include national parks, are developing training examples for local residents and the provision of guide services themselves. Case studies present the unique wilderness guides project in the Šumava National Park. Emphasis is placed on the co-operation of public institution with local residents, which is one of the basic forms of participatory management of the territory. First, it's focused on the theoretical, general issues in terms of national parks, knowledge management and human resources management - especially in respect to current trends in employee savings in individual institutions. From the theoretical paradigms, Cohen's guide roles were analysed. The Šumava National Park was chosen as the case study, which is unique in terms of developing the concept of local guides training. This paper describes the development of this activity and the development of a two-stage division of the guides. Finally, the results are summarised with the emphasis placed on the indispensable role of each national park as a publicly established institution that is also economically among the major players in each region.
\end{abstract}

Keywords: Guides, National Park, Human Resources.

\section{Introduction}

Worldwide, concepts and new activities are being proposed and developed to attract more tourists and visitors within the sustainable areas of tourism and activities linked to them both in national parks as well as other protected or wildlife areas. Preserved nature becomes a major attraction. Some people want to experience nature on their own, others understand natural laws better, find inspiration or just relax during their spare time from pre-urbanised cities and ubiquitous networked technological interconnections.

Local actors are motivated by the trend to develop new, interesting and lucrative offers that can attract visitors in the form of services and follow-up activities. "Return to nature" has become an increasingly important trend in recent years and every region that has sufficient natural assumptions tries to exploit the economic potential. 
These such regions, not only regions in the Czech Republic, undoubtedly include national parks with preserved natural heritage and other protected areas with their natural jewels.

This paper analyses the services development by local guides as a specifically evolving offer in the Šmava National Park. The main attraction of this complementary service in the region isn't just the possibility to enjoy a guided tour in places where access is forbidden due to nature protection, but the programme itself prepared by the guides is the main attraction. More and more visitors prefer the ability of drawing information on the place itself from a trained professional's mouth, preferably directly from a local person.

Finally, the research states the given individual recommendations for destination management and management of national parks for further development of the area of tourists' interest, which has been developing dynamically, or to suggest possibilities for its further development in the future.

National parks, just like other protected areas are a matter of interest for visitors who are seeking engagement in recreation with the use of nature, i.e. tourism that's connected with nature. There are a number of conceptual models that present changes on the visitors' side in terms of quantity and "quality" of their activities, i.e. type activities, spatial and time models [3,11]. In addition, in parks and protected areas, which include many protected sites, the management's priority is very often aimed at preventing disturbances that might arise from excessive or careless use, i.e. making accessible to the public.

Through their work some authors $[11,8,12]$ deal with perspectives to minimise possible ecological changes, which is very important in terms of the monitoring factors that affect the intensity of the visitors' stays in given locations, as well as types of leisure time use, length of stay and conditions of individual services. It's the managers of individual national parks that often have the greatest influence on some of these factors and above all, thanks to their understanding of the protected areas which they manage, they can balance the interrelated relationship between nature and humans. Therefore, they can create long-term sustainable environmental management. [8] Authors dealing with these issues in the long term $[1,11]$ agree on several basic principles:

- Recreation, which is carried out in harmonisation with nature or more natureoriented recreation has an impact on soil, vegetation, animals, water, air and other ecosystem components.

- A given space for the relationship between ecological change and use, can be described in individual steps or in linear functions.

- Visitors' behaviour in nature, their choice of leisure time use and their movement in the space including the length of their stay in it, is one of the first determinants of ecological disturbances.

On one hand, personnel policy and management policy are related to the issues of nature conservation and visitor policy and on the other hand, they are balanced with the correct nature conservation policy. 
Human resources and human resources management, sometimes also referred to as human capital [1] management or HR, is a process area within an organisation that deals with the management and development of human resources. It includes comprehensive personnel work, i.e. a variety of procedures and different management methods for managing human resources - for working with people in an organisation. From recruitment, is entering into employment, personal development up to payroll. In practice, various terms are used, such as personnel administration, personnel management, human resources management or human capital management. There is no major difference between them from a practical point of view, but they are theoretical concepts of personnel work and its place within the organisation - from simple staff management to active work with human capital.

Human resources management isn't limited to the HR manager and other personnel department staff, it also concerns practically every manager in the organisation. Human resources management is often applied in the past to the management of national parks. [7, 10] Addressing specific aspects is the subject of even later research, often with the focus and specifics of a given country.[9,14,16]

\section{Methods}

The main method for specifying Human Resources Management in national parks is the case study. The study analyzes the contribution of the wilderness guides in the Šumava National Park.

The trainings of local guides started in 2006. The participants have provided their services since 2008 with the coordinating role of the Šmava National Park Administration. The database of the trained local guides, who are active, is accessible on the websites of the trainers (www.npsumava.cz). The guiding services are also promoted in a leaflet for public, which is handed out on many places in and outside the national park region, above all in information and visitor centres.

All the data for this case study were collected from the local guides themselves using the contacts on the website. There were also made some face-to-face interviews with ten most experienced guides as well as with their coordinator, who is responsible for the public use of the Šumava National Park.

\section{3 Šumava National Park - case study}

\subsection{Local guides}

Public institutions, which also include national park administrations, are under constant pressure from the point of view of staff savings and not increasing their numbers [4]. The lack of adequate personnel and managerial resources to provide well-designed, sufficient promotional services [2] is also closely linked to this fact, although these services are very important locally, nationally and globally. Dearden \& Rollins [6] reports that they have come to a critical position in Canada. As a result, 
they state it was necessary to change access to these, from the public side, demanded activities and change the management of this segment. Their example has been used to support tour operators and guides who have an important and influential role in providing information, interpreting and guiding individual groups to nature. It also states that, despite reasonably widespread support, relatively little attention is paid to the guide's role $[13,15,17]$.

Studies that recognised and investigated the guide's role, included the Cohen model [5] as the basis for exploring the guide's role. Cohen [5] first conceptualized the guide's role in four different sub-roles of leadership.

The orientation of the "externally managed" guide's role is focused on organisation and management (supporting roles) and facilitating meetings with host groups (interaction roles). In these roles, the tour guide must meet both the individual and the group needs of the party, through resources outside of the group tour.

The "tourist guide" role "internally" focused, includes leadership in the form of social interaction (social roles) and dissemination of information (communicative roles) and these needs are summarised as follows within the Cohen's four-role tourism guide:

- instrumental roles: focus on direction, navigation, access to territory and security,

- inter-rational roles: focus on representing the area in a non-threatening manner and organisation,

- social roles: focus on tension management, social integration, as well as cohesion and the use of humour and entertainment for maintaining and building group morale,

- communication roles: focus on selecting the groups' points of interest, disseminating correct information and translating an unknown person (modified by Cohen 1985).

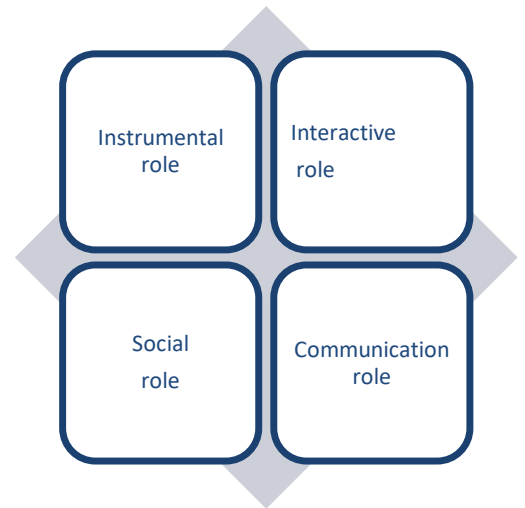

Fig. 1. The guide's roles 


\subsection{Guides in Šumava National Park}

The Šmava National Park is the largest national park in the Czech Republic with a total area of $690 \mathrm{~km}^{2}$. It was established in 1991 by Government Regulation No. 163/1991. The Šumava National Park Administration is a resort organisation for the Czech Republic Ministry of the Environment, which has a total staff of 265 (2016) and a total state budget contribution amounting to 274,370.27 CZK (2016), which is steadily decreasing at the expense of the contribution to the activity.

The Šumava National Park Administration has been developing local guides training since 2006. From the Czech point of view, it's a rare and in a way unique activity, which not every national park develops within its services portfolio. Within the Czech Republic, the Šumava National Park has so far been unique in regard to this activity. This activity started on the basis of numerous debates on the existence and benefits of the Šumava National Park. The debate went across both the political and the broad social spectrum. The questions mainly concerned the extent of nature protection, the accessibility of the strict protected zone that is inaccessible to ordinary public, the development of services in the area of tourism for visitors to the National Park, etc. In 2006, one of the demands for the National Park's top management was to create a guided tour of the Sumava Mountains and then start implementing it.

Based on this concept, a two-stage programme was developed to create a network of guides. The first stage consisted of the trained Šumava Guides and the second stage Wilderness Guides, recruited from the local Šumava guides, see Fig. 2.

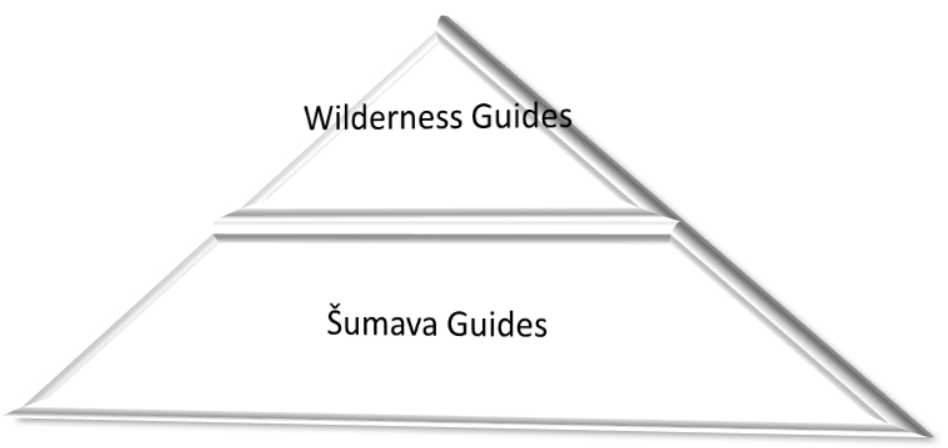

Fig. 2. Hierarchy of Guides in the Šumava National Park

A call for candidates and volunteers to participate in this new project was launched within this programme. The main organiser was the Šumava National Park Administration in co-operation with experts from a number of institutions (Czech Republic Academy of Sciences, Museum of Bohemian Forest, University of South Bohemia in České Budějovice, Šumava Regional Development Agency, etc.) and together with other practical guides. The whole project co-ordinates the so-called co- 
ordinator for the Šumava National Park Administration, who synchronises the necessary activities.

The prerequisite was that the candidates for guide course come from the National Park's region. The compulsory 8-day training consisted of both the theoretical lectures on the Sumava topic and practical examples of the guide's work. Signed participants were trained in two stages, theoretically as well as practically. The programme was fully completed by experts from the Šumava National Park Administration, as well as external experts from various fields and also from relevant institutions. The final part of the training was the preparation and execution of a model walk to nature. The individual has selected the site independently for the entire group, of course again under the supervision of experts from the Sumava National Park Administration.

Training local guides took place in three cycles in 2006, 2008 and 2009. A total of 71 participants were trained mainly by locals with a deep interest in the Šumava region and with good prerequisites for guide activities. The most beneficial part of this training was the evaluation of both the trainers and the participants themselves, the practical demonstration of a model guide for the entire "learner" group. Upon successfully completing this training, each participant received a certificate for the training completion and a badge with a guide's licence from the hands of the National Park Administration's Director.

The average cost of training each individual, including lecture fees, study materials, as well as boarding and accommodation during the courses, amounted to 7,500 CZK. Subsidies from UNEP GEF funds covered approximately $60 \%$ of the cost. The participants themselves paid a fee of 1,500 CZK and any other costs were paid by the course organisers. The Šumava landscape and nature guide helps all visitors to discover Šmava from a different point of view, from the point of view of local people with knowledge of nature, animals, plants, as well as local history and culture. The task of each local guide is to introduce the visitor to their native region, to which they have a personal positive relationship that seeks to transfer positive perceptions to the participant of each particular guide.

The Wilderness Guides are recruited from the trained Šumava Guides, there are currently around 30 of them. The difference between the first and second level guides is that the Wilderness Guides undertake further follow-up training annually and besides that, they must be physically competent due to the difficult terrain excursions and an active interest in contemporary events in the region is a matter of course, as they present it and must also be able to respond to questions about current media and public media issues.

Excursions to the wilderness are offered as one-day and to a lesser extent, two-day tours. (The two-day tours were first introduced in 2009 and then regularly since 2016). The fee for the guide ranges from $190 \mathrm{CZK}$ to $450 \mathrm{CZK}$, derived from the length, difficulty and accessibility of the route. The price for a two-day tour to the wilderness is set at $900 \mathrm{CZK}$. Each participant, of course, pays all the costs associated with staying in Sumava, in addition to the guide fee, which bring other direct economic gains for the Šumava National Park region, which included a total of 269,702 CZK in 2016. 
Given the fact that the National Park and the Protected Landscape Area of Šumava is located on the border between Austria and Germany, it's an enormous positive if the guide speaks German or English, especially for incoming media representatives or tour operators from abroad. As far as language for wilderness guides is concerned, German language is the strongest(14) followed by English(10). Russian or French language are also represented, but to a very minor extent, as is evident from Fig. 3.

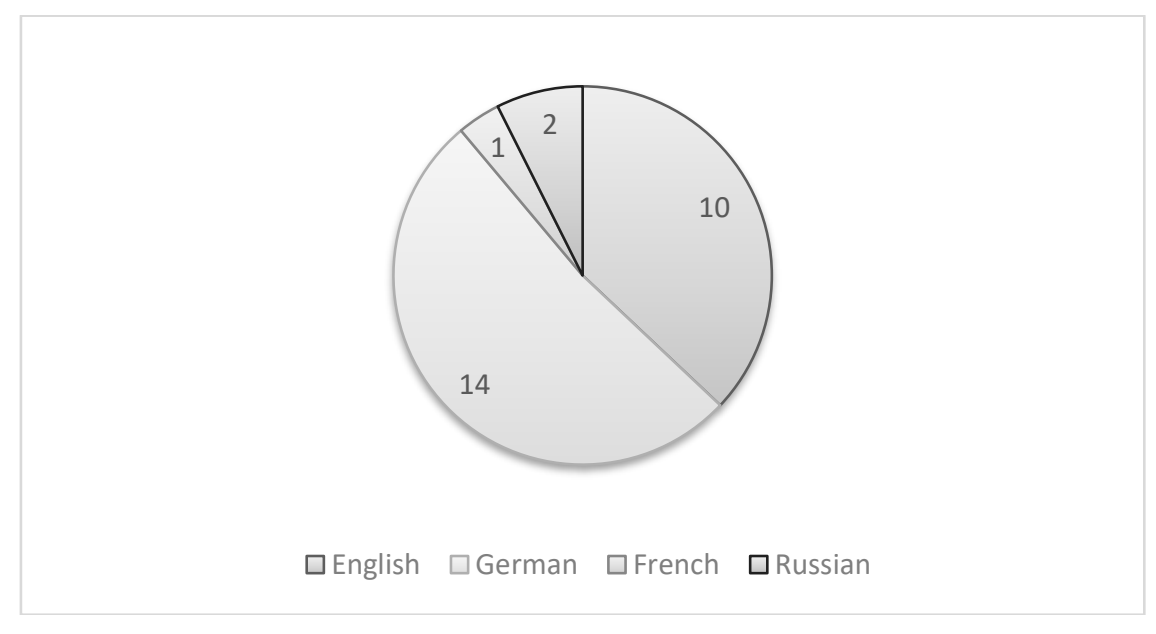

Fig. 3. Wilderness Guides' Language Skills

The gender ratio for wilderness guides is slightly to the benefit of women. In total: 16 women and 14 men. In conclusion, regarding Wilderness Guides' we must state that they're mostly self-employed people, who to a certain extent, can participate at any time during the week regardless whether it's a working day or a weekend.

\section{Conclusion}

An example study in the Šumava National Park shows that the programme of creation or extension of the current offer through Šumava guides or wilderness guides has a strong reputation on the visitors' side. The provided co-ordinator has to work continuously on the development of this activity. Updating the offer and new programmes, especially in the form of new routes and maintains and increases the attractiveness for existing and new entrants. The extension of this uniquely environmentally friendly and economically beneficial and socially appropriate activity makes it a model example of sustainable activity in the National Park Region, i.e. in a particularly preserved natural environment with the most strict nature protection form in the Czech Republic, regarding legislation. 
All financial income generated directly by the provision of guide services flows into the pockets of local residents, who are therefore highly motivated for the best possible performance. The Šumava National Park Administration indirectly benefits from their activities, which, through the trained guides, transfers their own information, as well as views and philosophy to the region's visitors. The main benefit is the increased acceptance of the territory's status, which is the national park and which can be seen in many respects as a negative fact for the region's economic development. Nature conservation plays a role here as a key factor for the sustainability and development of the region's economy. The entire National Park region benefits from the expansion of the tourist offer, which includes tourism to the ever stronger pillars of the region's economic development.

The main recommendations follow up:

- Education of people helps to understand the goals of the nature protection.

- Training of local inhabitants increases their acceptance of the national park.

- From financial income by locals from the availability of the national park profits even the nature protection, incl. the nature protection body.

- Development of the tourism sustainable activities supports the sustainable development of the national park region.

The Šumava National Park is therefore a significant player in the region not only on the basis of a well-known public institution, a significant employer, an important development partner and a tourist investor but also an exemplary partner for inspiration and the development of other types and activities in the field of tourism in its friendly form.

Acknowledgements. The paper was created with the support of the internal specific research titled "Evaluation of Investments in the Industry 4.0 Concept" of the Faculty of Informatics and Management of the UHK.

\section{$5 \quad$ References}

1. Becker, B.S.: Human Capital: A Theoretical and Empirical Analysis, with Special Reference to Education (3rd ed.). University of Chicago Press. (1993).

2. Boo, E.: Ecoturismo: Potenciales y escollos. World Wildlife Fund / Concervations/Fundation. USAID. Washington D.C. (1990).

3. Buckley, R.: Enviromental impacts of Ecotourism. CABI. Wallingfort.UK. (2004),

4. Butler, R.W., Boyd, S.W.: Tourism and National parks - Issues and implications. Stephen Boyd is Senior Lecturer in the Geography Division Staffordshire. (2000).

5. Cohen, E.: The tourist guide - the origins, structure and dynamics of a role. Annals of Tourism Research, 12(1), 456-77. (1985).

6. Dearden, P., Rollins, R.: Parks and protected areas in Canada: Planning and management. Toronto: Oxford University Press. 2nd Edition 3-20. (2002).

7. Donahue, J. (ed.). Wildlife in Parks: Policy, Philosophy, and Politics. Special issue of The George Wright Forum 14(1), 15-55. (1997).

8. Hammitt, W.E., Cole, D.N., Monz, C.A.: Wildland Recreation: Ecology and management. John Willay ans Sons. New York.NY. (2015) 
9. Kideghesho J.R., Røskaft, E., Kaltenborn, B.P.:Factors influencing conservation attitudes of local people in Western Serengeti, Tanzania, Biodiversity and Conservation, vol. 16, no. 7, pp. 2213-2230, 2007.

10. Leopold, A.S., Cain, S. A., Cottam, C. M. et al.: Wildlife management in the national parks. Transactions of the North American Wildlife and Natural Resources Conference 28, 28-45.(1963).

11. Monz, C.A., Pickering, C.M., Hadwen, W.L.: Recent advances in recreation ecology and the implication of different relationships between recreation use and ecological impacts. Front. Ecol. Environ. 11(8), 441- 446. (2013)

12. Newsome, D., Moore, S.A., Dowling, R.K.: Natural area tourism. Ecology, Impacts and Management. 2nd ed Chanel View Publication. Clevedon.UK. (2012).

13. Pond, K.L.: The professional guide: Dynamics of tour guiding. New York: Van Nostrand Reinhold. (1993)

14. Rands, M.R.W, Adams, W. M., Bennun, L. et al.: Biodiversity conservation: challenges beyond 2010, Science, 329(5997): 1298-1303. (2010).

15. Ryan, C., Huyton, J.: Who is interested in Aboriginal Tourism in the Northern Territory, Australia? A cluster analysis. Journal of Sustainable Tourism, 8(1): 52-87. (2000).

16. Vodouh^e F. G., Coulibaly, O., Ad'egbidi, A., Sinsin, B.: Community perception of biodiversity conservation within protected areas in Benin, Forest Policy and Economics, 12(7): 505-512. (2010).

17. Weiler, B., Davis, D.: An exploratory investigation into the roles of the nature-based tour leaders. Tourism Management, April, 91-98. (1993). 